\title{
Recurrent Cushing Disease
}

National Cancer Institute

\section{Source}

National Cancer Institute. Recurrent Cushing Disease. NCI Thesaurus. Code C153340.

The reemergence of Cushing disease after a period of remission. 